\title{
AFINIDADES ENTRE OS OUTSIDERS WALTER BENJAMIN E OSWALD DE ANDRADE 1
}

Filipe Ceppas

para Leandro Konder, antropófago revolucionário (in memoriam)

\begin{abstract}
RESUMO
Este artigo explora afinidades entre Walter Benjamin e Oswald de Andrade a partir de alguns problemas semelhantes e conceitos comuns aos dois autores, aproximando-os sobretudo no que diz respeito à posição de outsider que ambos tiveram frente à militância política e institucional. Partindo do conceito de "primitivo" ou "arcaico" (e outros conceitos correlatos, como "barbárie", "selvagem" e "violência"), o artigo procura mostrar ao menos quatro pontos de contato entre os autores: (1) a aguda percepção do caráter dessublimador da modernidade, sobretudo a partir da poética de Baudelaire; (2) a questão do matriarcado; (3) o desafio de pensar a técnica e imagem numa perspectiva imanente às transformações artísticas do século XX; e (4) a dimensão erótica, afetiva ou amorosa de uma possível perspectiva política libertária e revolucionária.
\end{abstract}

Palavras-chave: Benjamin. Oswald. Arcaico. Política. Revolução.

\section{AFFINITIES AMONG THE OUTSIDERS WALTER BENJAMIN AND OSWALD DE ANDRADE}

\begin{abstract}
This article explores affinities between Walter Benjamin and Oswald de Andrade from some similar problems and concepts common to the two authors, which brings them closer to an outsider position they both had in the face of institutional and political militancy. Starting with the concept of the "primitive" or "archaic" (and other related concepts such as "barbarism", "savage" and "violence"), the article seeks to show at least four points of contact between the two authors: (1) the acute perception of the desublimated character of modernity, mainly since the poetics of Baudelaire; (2) the matriarchy; (3) the challenge of thinking about technique and image from an immanent perspective of the artistic transformations on the twentieth century; and (4) the erotic, affective, or loving dimension of a possible libertarian and revolutionary political perspective.
\end{abstract}

Keywords: Benjamin. Oswald. Archaic. Politics. Revolution.

\footnotetext{
${ }^{1}$ Este texto deve muito a Fernando Gerheim e nossas conversas sobre Benjamin e Oswald. Parte importante da motivação para esse trabalho vem da leitura do artigo "Benjamin et la révolution" de Leandro Konder (1994).
}

UFRJ, Doutor (PUC-Rio). Brasileiro, residente em Rio de Janeiro, Email: filcepps@gmail.com 


\section{INTRODUÇÃO}

São muitas as aproximações entre Walter Benjamin (1892-1940) e Oswald de Andrade (1890-1954), e o contínuo fascínio que exercem enquanto referências teóricas em perspectivas políticas e culturais de esquerda não é a menor delas. ${ }^{2}$ Elemento importante neste sentido é o compromisso, assumido de modo idiossincrático por ambos, com o conceito marxista de dialética e com uma perspectiva libertária, revolucionária. A intensidade desse fascínio, assim como a infelicidade dos desencontros, em suas trajetórias, com a militância de esquerda, parece proporcional à violência com que eles deslocam as ideias dos lugares onde se esperaria encontrá-las. Esse é um aspecto relevante para explicar porque ambos permaneceram outsiders, mantidos no ostracismo, deixados por tanto tempo à margem. A reabilitação em círculos de esquerda, desde o final da década de 1960, parece ter a ver com uma crescente capacidade geral para acomodar essa violência ou a radicalidade dos métodos por eles empregados (o estilo da escrita, as formas de pensar, os conceitos adotados) e, também, obviamente, com a percepção da importância mesma de suas ideias para as lutas políticas atuais.

Benjamin e Oswald podem ser ditos outsiders porque viveram à margem da academia e nunca conseguiram aderir totalmente a uma perspectiva ideológica, ou nunca foram verdadeiramente aceitos, incorporados à militância marxista, mesmo que o tenham efetivamente ensaiado ou desejado. Eles parecem ter sido rejeitados com força inversamente proporcional à eventual intensidade de seus desejos ou efetivas tentativas de participação política. Essa noção um pouco fluida de outsider aplicada a Benjamin e Oswald, como "pensadores marginais", que caminharam à margem, nos convida a revisitar a questão da atualidade

\footnotetext{
${ }^{2}$ A aproximação entre esses autores soa, de início, curiosa, se levamos em conta as enormes distâncias no que diz respeito às suas personalidades e ao estilo de pensamento $e$ de escrita. No registro biográfico-anedótico, é possível imaginar os dois corpos volumosos se esbarrando a contragosto na livraria La maison des amis des livres, de Adrienne Monnier, importante amiga tanto de Benjamin como de Tarsila do Amaral, esposa de Oswald nos anos 1920.
}

UFRJ, Doutor (PUC-Rio). Brasileiro, residente em Rio de Janeiro, Email: 
política de suas ideias, após o resgate de ambos, transformados, em certa medida, em autores "pop", popularizados, assim como assimilados a novos e importantes âmbitos de investigação acadêmica.

Na política, a ideia de outsider, ou de pensador-militante à margem, soa antinômica. É como se houvesse um "apelo político", uma chamada ao político, à militância (ou uma chamada do político, da militância), que fracassa por algum motivo. É um fracasso paradoxal, porque corresponde, ao mesmo tempo, à única atitude correta, à única experiência possível de ser vivida a partir das condições existenciais e exigências teóricas e literárias desses autores. Neste sentido, o outsider, o pensador marginal que eles foram, não é nunca apenas aquele que ficou simplesmente à margem, mas é aquele que ficou à margem por, de certo modo, simultaneamente ter e não ter desejado aí permanecer, iluminando a própria margem com esse desencontro com a militância.

Nossa hipótese de trabalho é que o entrelaçamento de temas e problemas recorrentes nas obras de Benjamin e Oswald não é fruto de mera coincidência, de uma atenção a temas e problemas mais gerais em voga na primeira metade do século XX. Haveria uma afinidade no modo como ambos lidaram com esses temas e problemas, afinidade intimamente relacionada à condição de pensadores outsiders. Proponho explorar essa afinidade, estrategicamente, partindo do conceito do primitivo ou do arcaico. Não que esse conceito percorra de maneira homogênea todos os pontos de contato mais importantes entre os dois autores, mas é um conceito central e incontornável. Dentre os pontos de contato a explorar, destaco ao menos quatro: (1) a aguda percepção do caráter dessublimador da modernidade, sobretudo a partir da poética de Baudelaire, sua importância e desdobramentos não apenas para a arte modernista, mas para a compreensão das condições da vida na contemporaneidade; (2) a referência a Bachofen, isto é, a questão do matriarcado no desenvolvimento de suas derradeiras especulações histórico-antropológicas; (3) o desafio de pensar a técnica e imagem numa perspectiva imanente às transformações artísticas do século XX; e (4) a dimensão erótica, afetiva ou amorosa de uma possível perspectiva libertária e revolucionária.

UFRJ, Doutor (PUC-Rio). Brasileiro, residente em Rio de Janeiro, Email: 
Impossível tratar, aqui, de todos esses aspectos com a profundidade que cada um deles exige. ${ }^{3}$ Procuro somente indicar alguns pontos que nos ajudam a traçar um paralelo entre os dois autores, desde uma preocupação com sua dimensão política. A política na figura do outsider, como elemento de elo entre os autores, expressa a dimensão estrutural e complexa dessas proximidades temáticas e conceituais. Trata-se de ressaltar a ambição transformadora, politicamente revolucionária, sempre latente, nas abordagens das quatro temáticas acima indicadas - a modernidade, 0 matriarcado, a técnica e o amor - que Benjamin e Oswald desenvolvem em conexão com o conceito do primitivo.

\section{Antropofagia e barbárie}

O termo "primitivo" não recobre indistintamente as imagens do selvagem, do bárbaro, do mítico e do arcaico. Esses termos não são sinônimos e é preciso atentar para algumas distinções. Podemos começar a explorá-lo a partir do reconhecimento da oposição dialética entre "barbárie" e "cultura", tal como aparece num importante fragmento das Passagens:

A barbárie está inserida no próprio conceito de cultura: como conceito de um tesouro de valores considerado de forma independente, não do processo de produção no qual nasceram os valores, mas do processo no qual eles sobrevivem. Desta maneira, servem à apoteose deste último, não importando o quão bárbaro possa ser. (BENJAMIN, 2007, p. $509\left[\mathrm{~N} \mathrm{5a,7])^{4 }}\right.$

Ponto de partida fundamental: a manutenção da civilização é identificada com uma condição primitiva, bárbara, violenta. As imagens aproximadas do primitivo, do bárbaro, da violência, da destruição, em Benjamin, são também quase sempre imagens possíveis de um novo começo. De imediato, são imagens da percepção daquilo que a condição da

\footnotetext{
${ }^{3}$ Vale destacar algumas aproximações entre Benjamin e Oswald já existentes na fortuna crítica, em especial naquela acerca do antropófago brasileiro: FABRI (2011), HELENA (1985), LIMA (2012), MAIO (2010), NODARI (2007) e SILVA (2017).

4 "Die Barbarei steckt im Begriff der Kultur selbst: als dem von einem Schatze von Werten, der unabhängig zwar nicht von dem Produktionsprozeß, in welchem sie entstanden, aber unabhängig von dem, in welchem sie überdauern, betrachtet wird. Sie dienen auf diese Weise der Apotheose des letztern, wie barbarisch der immer sein mag" (GS 5, p. 584).
}

UFRJ, Doutor (PUC-Rio). Brasileiro, residente em Rio de Janeiro, Email: 
modernidade tem de fascínio e de força anti-burguesa: é a associação da condição de vida nas grandes metrópoles com uma dimensão selvagem. Em Benjamin, assim como em Oswald, a imagem do primitivo ou do bárbaro estará sempre marcada por essa dimensão conflitual irredutível.

Em 1924, no Manifesto da Poesia Pau-Brasil, Oswald anunciou que a "reação contra todas as indigestões de sabedoria" seria nos mantermos "bárbaros, crédulos, pitorescos e meigos"; nosso principal desafio seria conjugar floresta e escola (OSWALD, 1972, 9-10). ${ }^{5}$ Desde então, a pergunta sobre o que é esse nosso "ser bárbaro", ou o que nos vem da floresta, o que é em nós floresta, é uma pergunta que reverbera em diversas direções, em coloridos diferentes. Em 1924, além das qualidades de "crédulos, pitorescos e meigos", há uma indicação precisa, logo no primeiro aforisma do manifesto, sobre a natureza conflitual dessa "nossa bárbarie":

O Carnaval no Rio é o acontecimento religioso da raça. Pau-Brasil. Wagner submerge ante os cordões de Botafogo. Bárbaro e nosso. A formação étnica rica. Riqueza vegetal. $O$ minério. A cozinha. $O$ vatapá, o ouro e a dança. (OSWALD, 1972, p. 5, grifo nosso)

O "carnaval no Rio" é a riqueza étnica, o melting pot: é o pirata, o índio, a odalisca, o pierrot, a baiana, mas é também, e sobretudo, uma experiência, por ilusória que seja, de comunhão e catarse. A comunhão se dá, entretanto, no conflito, não através de conciliação. Wagner submerge ante os cordões de Botafogo, em meio ao delírio dionisíaco do carnaval. Essa “experiência Pau-Brasil”, possibilitada pela formação rica, étnica, histórica, cultural, será reembaralhada quatro anos mais tarde, em 1928, sob o prisma da antropofagia. A natureza da experiência antropófaga é fundamentalmente agonística, conflituosa, embora também alegre, festiva - antinomia que nos força sempre a repensar os limites das nossas concepções de guerra, violência e paz. Nesta fase antropófaga, a comunhão se dá pela devoração do outro, que é um ritual de guerra e vingança das tribos canibais. A crise da filosofia messiânica, de 1950, terminará com uma formulação inequívoca:

\footnotetext{
${ }^{5}$ Oswald não utiliza o termo "conjugar". O adotamos no sentido o mais neutro possível, isto é, de ter sempre em mente a conjunção floresta e escola.
}

UFRJ, Doutor (PUC-Rio). Brasileiro, residente em Rio de Janeiro, Email: filcepps@gmail.com 
13ํ) Que o homem, como o vírus, o gen, a parcela mínima da vida, se realiza numa duplicidade antagônica, - benéfica, maléfica que traz em si o seu caráter conflitual com o mundo. (OSWALD, 1972, p. 129)

Contra toda leitura de Oswald eventualmente refém da suposta centralidade do caráter metafórico da antropofagia, que se reduziria a "nos aproveitarmos livremente daquilo que interessa na cultura alheia" (o que pode significar muitas coisas, mas que é, sem dúvida, também uma espécie de grito de alforria contra todo critério heterônomo ou colonialista de valoração cultural), seria preciso identificar os demais elementos prismáticos que compõem, de forma tensa, conflitual, a antropofagia como visão de mundo, como Weltanschauung.

\section{0 selvagem na modernidade}

Nas Passagens e em Baudelaire, um lírico no auge do capitalismo, Walter Benjamin compilou as insólitas aproximações entre a modernidade das grandes cidades e alguns termos e temas associados ao "primitivo", recorrentes na literatura francesa da segunda metade do século XIX. Em Les Misérables, III, Victor Hugo escrevia: "As cidades, como as florestas, têm seus antros onde se esconde tudo o que elas têm de mais pernicioso e de mais temível". (BENJAMIN, 2007, 458 [L 5, 4]; ver, ainda, [M 13, 4]). Baudelaire, em Fusées, Ihe faz eco:

O homem... está sempre... em estado selvagem! O que são os perigos da selva e da pradaria comparados aos choques e conflitos cotidianos do mundo civilizado? O homem que enlaça a sua vítima no boulevard, ou aquele que trespassa sua presa nas florestas desconhecidas, não é ele ... o mais perfeito predador? (apud BENJAMIN, 2007, p. $486[M 14,3])^{6}$

\footnotetext{
${ }^{6} \mathrm{O}$ trecho original completo é: "Quoi de plus absurde que le Progrès, puisque l'homme, comme cela est prouvé par le fait journalier, est toujours semblable et égal à l'homme, c'està-dire toujours à l'état sauvage. Qu'est-ce que les périls de la forêt et de la prairie auprès des chocs et des conflits quotidiens de la civilisation? Que l'homme enlace sa dupe sur le boulevard, ou perce sa proie dans des forêts inconnues, n'est-il pas l'homme éternel, c'està-dire l'animal de proie le plus parfait ?" (BAUDELAIRE, 1952, p. 70-71).
}

UFRJ, Doutor (PUC-Rio). Brasileiro, residente em Rio de Janeiro, Email: filcepps@gmail.com 
Benjamin comenta: "Tenta-se dominar as novas experiências da cidade dentro do quadro das antigas experiências da natureza transmitidas pela tradição. Daí os esquemas da floresta e do mar" (BENJAMIN, 2007, 490 [M 16a, 3]). O próprio quadro das antigas experiências e seus esquemas com isso se transformam. De início, na metrópole, o "estado selvagem", o "bárbaro", é compreendido na comparação com uma floresta ameaçadora, tendo por consequência o isolamento. Benjamin cita Valéry: "O habitante dos grandes centros urbanos (...) incorre novamente no estado de selvageria, isto é, de isolamento." (apud BENJAMIN, 1989, 124) ${ }^{7}$. A isso se relaciona toda a crítica marxista à alienação, ao isolamento do operário transformado em mera força de trabalho, em mercadoria (cf. BENJAMIN, Paris do segundo império, 1989, 54-55 [GS1, 560-561]). Mas a comparação encerra também uma face positiva, que parece evidente ao longo de todo o texto sobre Baudelaire e ao longo das Passagens. E é curioso que Benjamin não cite o seguinte trecho de $O$ pintor da vida moderna, onde Baudelaire aproxima o selvagem e a criança neste registro:

As raças que nossa civilização, confusa e pervertida, trata com naturalidade de selvagens, com um orgulho e uma enfatuação absolutamente risíveis, compreendem, tanto quanto a criança, a alta espiritualidade da indumentária [de la toilette]. O selvagem e o baby provam - por sua aspiração ingênua em relação a tudo o que é brilhante, às plumagens multicores, aos tecidos cintilantes, à majestade superlativa das formas artificiais - sua aversão pelo real, e testemunham, dessa forma, à sua revelia, a imaterialidade de sua alma. (BAUDELAIRE, 1988, p. 56)

As Passagens tornam latentes os contrastes entre dimensões obscuras e luminosas do selvagem como uma das figuras centrais da modernidade, ao lado do flanêur, da prostituta e do trapeiro. Os fragmentos relevantes estão concentrados na sessão $\mathrm{M}, \mathrm{O}$ flanêur, começando com as citações de Cooper [M 11a, 5] e do romance de Alexandre Dumas, Les

\footnotetext{
7 "Le civilisé des villes immenses revient à l'état sauvage - c. à d. isolé..." Benjamin usa o termo alemão Wildheit para traduzir o original "l'état sauvage". Ver GS 1, 630. O aforismo completo de Valèry é: "O civilizado das cidades grandes volta ao estado selvagem, isto é, de isolamento, porque o mecanismo social permite que ele esqueça das exigências [nécessité] da comunidade e perca o sentimento de conexão entre os indivíduos, antes sempre despertado pela necessidade [par le besoin]. Todo o aperfeiçoamento do mecanismo social torna inúteis os atos, os modos de sentir, as aptidões para a vida comum."
}

UFRJ, Doutor (PUC-Rio). Brasileiro, residente em Rio de Janeiro, Email: filcepps@gmail.com 
Mohicans de Paris. Aqui, o selvagem não é uma figura como as outras, como o flanêur ou o trapeiro. Ele é um elemento estranho (no sentido freudiano da palavra unheimlich, o estranho-familiar), que reforça aquilo que Caillois, citado por Benjamin nas Passagens, chama de uma "representação fantasmagórica de Paris (e da grande cidade em geral)"; ${ }^{8}$ é uma imagem que põe em movimento, por sua própria natureza fantasmagórica, irreal, a centralidade das relações entre imagem, modernidade, cidade, história e o primitivo ou arcaico, sob o signo da exploração capitalista.

Se existe alguma outra imagem capaz de abranger a condição dos "homens inferiores" na cidade grande, esta é a dos filhos de Caim. Comentando um poema de Baudelaire, Abel e Caim, ${ }^{9}$ Benjamin afirma:

Caim, o ancestral dos deserdados, nele [no poema de Baudelaire] aparece como fundador de uma raça que não pode ser senão a proletária. Em 1838, Granier de Cassagnac publicou sua História das Classes Operárias e das Classes Burguesas. Esta obra soube proclamar a origem dos proletários: formavam uma raça de homens inferiores, resultante do cruzamento de ladrões e prostitutas. (...) Exatamente nessa acepção aparece em Baudelaire a raça originária de Caim. Obviamente, ele não teria podido defini-la. É a raça dos que não possuem outro bem que não a sua força de trabalho. (BENJAMIN, 1989, p. 19)

As imagens do selvagem e dos filhos de Caim se aproximam, curiosamente, porque se há uma maldição equivalente nos trópicos, esta seria a raça dos selvagens identificados por jesuítas e viajantes como os filhos de Tomé, mito analisado por Sérgio Buarque de Holanda em Visões do Paraíso (HOLANDA, 2000). Embora pudéssemos ser tentados a identificar esses filhos de Tomé, os índios selvagens, também com a raça de Abel, aquela que, segundo o poema, somente "frui, come e dorme", e para quem Deus "sorri bondosamente", essa aproximação estaria bloqueada no poema, uma vez que a identificação da raça "abençoada" recai, de modo irônico, neste contexto, sobre a burguesia.

${ }^{8}$ Citação de Roger Caillois, "Paris, mythe moderne" (Benjamin, 2007, p. 483 [M 12, 1]).

9 "Race d'Abel, dors, bois et mange / Dieu te sourit complaisamment. / Race de Caïn, dans la fange / Rampe et meurs misérablement".

UFRJ, Doutor (PUC-Rio). Brasileiro, residente em Rio de Janeiro, Email: filcepps@gmail.com 


\section{A dialética e o arcaico}

Os temas correlatos do selvagem, do primitivo, do arcaico, são motivos que articulam dimensões fundamentais da psiquê e da história, a ontogênese e a filogênese, debate sobre a cultura do qual Totem e Tabu de Freud, de 1913, é um dos exemplares mais conhecidos. O arcaico, em Benjamin, comparece desde cedo em sua obra, e de modo crucial em "Sobre a linguagem em geral e sobre a linguagem dos homens", texto de 1916, e em dois textos de 1921: "Destino e caráter" e "Para a crítica da violência" (farei referência sobretudo a este último texto, quando voltarmos à questão do engajamento político e da revolução). $\mathrm{Na}$ época das Passagens, em que Benjamin se dedica de modo mais sistemático a elaborar uma "história primeva" do capitalismo, numa perspectiva que conjuga marxismo e teologia, o tema volta ao primeiro plano e é longamente debatido com Adorno, com reflexos importantes nos textos então produzidos.

Em carta de 5 de abril de 1934 enviada a Benjamin, Adorno se refere à "questão central" dos dois amigos como sendo "a da coincidência do moderno com o arcaico". Ele caracteriza o arcaico "como uma função do novo", como sendo, "precisamente (...) o lugar de todas as coisas cuja a voz foi silenciada pela história" (ADORNO; BENJAMIN, 1999, 38). Mas a exigência de mediação, de tratamento dialético da questão, irá explicitar suas diversas e complexas camadas. Em suas cartas, Adorno fará reiteradas críticas ao "caráter insuficientemente dialético" do trabalho de Benjamin a esse respeito. Dentre os vários aspectos da contenda, destaca-se o medo que Adorno sentia de que o trabalho de seu amigo servisse para reforçar uma concepção arquetípica, reificada, paradoxal, porque simultaneamente mística e positivista, dos elementos críticos contidos nesse embate entre o arcaico e o tempo presente - o positivismo advindo do fato de que a reificação dos arquétipos congela a compreensão em momentos isolados que iluminam de modo apenas mistificador o presente. Parece haver, ainda, a crítica a um certo voluntarismo político a que esse tipo de concepção poderia levar; e o nome de Brecht é diversas vezes mencionado por Adorno neste UFRJ, Doutor (PUC-Rio). Brasileiro, residente em Rio de Janeiro, Email: 
sentido. Benjamin reproduz ou reelabora, de modo condensado, parte do debate em alguns trechos das Passagens, dentre os quais vale citar 0 seguinte:

O índice histórico das imagens diz, pois, não apenas que elas pertencem a uma determinada época, mas, sobretudo, que elas só se tornam legíveis numa determinada época. E atingir essa "legibilidade" constitui um determinado ponto crítico específico do movimento em seu interior. Todo presente é determinado por aquelas imagens que the são sincrônicas: cada agora é o agora de uma determinada cognoscibilidade. Nele, a verdade está carregada de tempo até o ponto de explodir. (Esta explosão, e nada mais, é a morte da intentio, que coincide com o nascimento do tempo histórico autêntico, o tempo da verdade.) Não é que o passado lança sua luz sobre o presente ou que o presente lança sua luz sobre o passado; mas a imagem é aquilo em que o ocorrido encontra o agora num lampejo, formando uma constelação. Em outras palavras: a imagem é a dialética na imobilidade. Pois, enquanto a relação do presente com o passado é puramente temporal, a do ocorrido com o agora é dialética - não de natureza temporal, mas imagética. Somente as imagens dialéticas são autenticamente históricas, isto é, imagens não-arcaicas. [...nicht archaische Bilder] (BENJAMIN, 2007, p. 504-505 [N 3, 1])

Logo no próximo aforisma [N 3, 2], recusando a ideia de "verdade intemporal", Benjamin critica o marxismo por não levar em conta que a verdade não é "apenas uma função temporal do conhecer, mas é ligada a um núcleo temporal que se encontra simultaneamente no que é conhecido e naquele que conhece." A não existência de uma "verdade intemporal" não impede que haja o eterno, e que este seja "muito mais um drapeado em um vestido do que uma ideia" [Das ist so wahr, daß das Ewige jedenfalls eher eine Rüsche am Kleid ist als eine Idee]. ${ }^{10} \mathrm{Na}$ avaliação da tortuosa tentativa de Benjamin em responder às objeções de Adorno, prevalece finalmente a percepção de uma firme distância adotada pelo primeiro em relação às desconfianças epistemológicas e metafísicas do segundo. Assim, a uma das críticas de Adorno, Benjamin reage do seguinte modo: "Quando você fala de uma 'apresentação olho-arregalado de meros fatos', você está caracterizando a atitude filológica apropriada". (9 de dezembro de 1938, ADORNO; BENJAMIN, 1999, 291).

${ }^{10}$ Buck-Morss (1989, p. 23) interpreta o drapeado no vestido como uma referência à moda, mas a imagem do drapeado faz eco a esse duplo vínculo entre o conhecido e quem conhece. Assim, Tom Gunning (2003, p. 129) propõe uma aproximação mais interessante com a experiência do detetive e o conceito de inconsciente ótico, que explora o espaço dentro do espaço, o tempo dentro do tempo.

UFRJ, Doutor (PUC-Rio). Brasileiro, residente em Rio de Janeiro, Email: filcepps@gmail.com 
Apesar de Benjamin admitir, de início (e, talvez, de modo irônico), seu "insuficiente domínio do arcaico" (carta de 7 de janeiro de 1935), ele continua a desenvolver seu pensamento, neste aspecto preciso, numa linha em grande medida dissonante à de Adorno. É verdade que os textos sofrem modificações significativas em função das críticas e o resultado é um complexo de distinções conceituais aberto a contínuas releituras e revisões (ficando sempre em questão o peso de motivações externas ao texto, como as exigências do Instituto de Pesquisa Social). Para além da difícil tarefa de compreensão desse denso emaranhado de conceitos, o "primitivo" aparece nos textos de Benjamin como uma senha para pensar a fonte ambivalente de toda força que o agora pode fazer despertar, ao reviver a imagem do passado como aquilo que ele guarda de revolucionário - seja somente porque, como indicamos no início, para Benjamin, em perspectiva coincidente com a de Adorno, a percepção da barbárie como condição da cultura é também condição para a sua superação. Mas o primitivo para Benjamin é sempre, simultaneamente, uma referência a dimensões inconscientes e profundas, positivas, relativas à natureza mimética, imagética e mística da linguagem.

A questão do primitivo está diretamente relacionada ao debate que Benjamin avança com relação à imagem e a técnica. Vê-se isso claramente na curta resenha do livro de Carl Albrecht Bernoulli sobre a obra de Bachofen, resenha publicada em 1926, bem antes, portanto, da redação do famoso ensaio sobre a obra de arte na época de sua reprodutibilidade técnica. Neste minúsculo texto, Benjamin já aponta para a necessidade de se elaborar a crítica a uma certa recusa apocalíptica da técnica, a partir da valoração das imagens como "componentes reais e ativos, em virtude dos quais um mundo mais profundo, revelado unicamente no êxtase, atua dentro do mundo dos sentidos mecânicos usando o ser humano como medium." (BENJAMIN, 2013a, 118) Como Benjamin indica, no ensaio mais elaborado sobre Bachofen, escrito entre 1934 e 1935, e que permaneceu inédito, não se trata de buscar na tese do matriarcado a defesa de um neopaganismo, mas o acesso a dimensões "ctônicas" da origem da propriedade, do Direito, da dominação masculina e dos limites da democracia ocidental (BENJAMIN, 
2016, 91-107). Oswald tomará para si, por volta de 1950, programa absolutamente coincidente, em nome da antropofagia.

Admitamos, de imediato, que as aproximações entre o matriarcado e a antropofagia, propostas por Oswald de Andrade são fantasiosas e temerárias. Mesmo Engels (que também se serve de Bachofen para desenvolver sua crítica à propriedade e ao patriarcado, em $A$ origem da família, da propriedade e do estado) fala, na maioria das vezes, em sociedades matrilineares (o que é diferente de um regime matriarcal, onde as mulheres mandam ou nunca se saberia quem é o pai) e se refere a diferentes agrupamentos sociais e períodos históricos, impossibilitando o esquema por demais simplista de Oswald, que identifica matriarcado com sociedades antropófagas e patriarcado com sociedades messiânicas. Mas a imprecisão ou a elasticidade desses conceitos em Oswald tem a virtude de lançar luz sobre oposições e temas importantes, muito semelhantes aos que interessavam a Benjamin, sobretudo aquele do caráter inconsciente e imagético da técnica, capaz de liberar as forças reprimidas no e pelo patriarcado, minando os princípios da herança paterna, do sacerdócio e da transcendência. A técnica aparece nos textos de Oswald também como uma força histórica destrutiva, de secularização, anti-messiânica. É importante ressaltar que Oswald usa o termo "messianismo" em um sentido cristão, de transcendência e salvação a partir da lei, do messias, do Deus cristão, sentido, em certos aspectos fundamentais, radicalmente distinto daquele associado às ideias de Benjamin.

\footnotetext{
...as civilizações que admitem uma concepção messiânica da vida, fazendo o indivíduo objeto de graça, de eleição, de imortalidade e de sobrevivência, se desolidarizam, produzindo o egotismo do mundo contemporâneo. Para elas, há a transcendência do perigo e a sua possível dirimição em Deus. ("Um aspecto antropofágico da cultura brasileira: o homem cordial", OSWALD, 1972, p. 143)
}

Para Oswald, a técnica - o jornal, o rádio, o carro, o cinema, o esporte, etc - possibilita a comunhão, a retirada dos seres humanos dessa condição de egotismo, de crença na salvação pessoal associada a um princípio transcendente; e sua potência, juntamente com o predomínio da nefasta mercantilização burguesa da vida, já desde o Renascimento, está UFRJ, Doutor (PUC-Rio). Brasileiro, residente em Rio de Janeiro, Email: 
relacionada a um "espírito construtivo", que Oswald chama de "avesso da Utopia" ( $A$ marcha das utopias, OSWALD, 1972, 166): uma "inocência construtiva", "ver com olhos livres". Podemos aproximar essa abordagem de Oswald e o conceito de barbárie positiva de Benjamin:

\begin{abstract}
Barbárie? De fato, assim é. Dizemo-lo para introduzir um novo conceito, positivo, de barbárie. Senão vejamos aonde essa nova pobreza leva o bárbaro. Leva-o a começar tudo de novo, a voltar ao princípio, a saber viver com pouco, a construir algo com esse pouco, sem olhar nem à esquerda nem à direita. Entre os grandes criadores sempre existiram os implacáveis, que começaram por fazer tábua rasa. Queriam uma prancheta limpa, foram construtores. Um desses construtores foi Descartes, que começou por reduzir toda a sua filosofia a uma única certeza: "Penso, logo existo". E foi dela que partiu. Também Einstein foi um desses construtores... (...) (BENJAMIN, 2016, p. 115-116)
\end{abstract}

Toda essa perspectiva de tábula rasa, enquanto força "descristianizadora", é historicamente, segundo Oswald, indissociável da descoberta das Américas, do contato com essa gente guerreira que comia gente:

A descoberta do Novo Mundo veio trazer ao panorama da cultura européia um desmentido paradisíaco. $O$ ecumênico cristão caía de um golpe. Do outro lado da terra - que era redonda e não chata e parada, com céu em cima e inferno embaixo - havia gente e gente que escapava por completo ao esquema valetudinário da Idade Média, o qual fazia desta terra um simples trânsito ( $A$ marcha das utopias, OSWALD, 1972, p.190)

À descristianização da vida, segue-se a descristianização da morte. Procura-se na América levar às últimas consequências a concepção estóica do primitivo ante a morte, considerada ato de devoração pura, natural e necessário. ( $A$ crise da filosofia messiância, OSWALD, 1972, p. 127)

A devoração pura, natural e necessária, é "não-violenta", ou, antes, ela é uma espécie de violência que o Direito, que lhe é absolutamente estrangeiro, não tem parâmetros para julgar - tema que encontramos no texto "Para a crítica da violência". No texto sobre Bachofen, Benjamin escreve que, na ordem imemorial, "a morte também não se associa a nenhuma destruição violenta" (BENJAMIN, 2016, 97).

UFRJ, Doutor (PUC-Rio). Brasileiro, residente em Rio de Janeiro, Email: filcepps@gmail.com 


\section{Erótica e revolução}

Uma dessas exigências, e não a menor delas, é que uma aspiração revolucionária, libertária, seja também uma liberação erótica. Neste sentido, não é mera coincidência que ambos, Benjamin e Oswald, tenham sido seduzidos a entrar no Partido Comunista (o que nunca aconteceu) graças, em grande medida, à paixão por duas mulheres liberadas e militantes, Asja Lacis e Pagú; o que, nos dois casos, longe de curtocircuitar a plena consciência do valor do difícil trabalho teórico e literário a cumprir, longe de implicar uma oposição esquemática entre amor e sentimento, de um lado, e razão e obra, de outro, revela uma precipitação da vida e da obra em suas mútuas implicações. Daí este dado bibliográfico não ser uma "questão menor". ${ }^{11}$ Os dois autores o explicitam em vários textos, e Benjamin o faz, também, de modo tangencial mas importante, em um texto fundamental para pensar a questão da revolução, o já mencionado "Para a crítica da violência", de 1920 (isto é, antes de suas mais sistemáticas e idiossincráticas aproximações às questões da dialética, do marxismo ou da revolução).

Neste texto, após analisar diversas figuras da violência relacionadas ao Direito, como a pena de morte, o direito de greve e a polícia, Benjamin reitera sua tese de que "toda violência como meio é ou instauradora ou mantenedora do direito" (BENJAMIN, 2013b, 136), para logo em seguida se perguntar pela possibilidade de "meios não-violentos para a regulamentação dos interesses humanos em conflito". Ele responde afirmando que isso ocorre em meio às "relações entre pessoas particulares", "onde o cultivo do coração deu aos homens meios puros para o entendimento" (idem, 139).

\footnotetext{
11 Vela mencionar a curiosa rejeição que alguns comentadores de Benjamin manifestam com relação à importância de Lacis na vida de Benjamin, a começar pela indelicadeza de Adorno e Scholem, quando retiram a dedicatória de Benjamin à Lacis da edição de Rua de mão única nas obras escolhidas, publicadas após a morte do autor. São fatos bastante documentados não apenas a importância afetiva de Asja Lacis na vida de Benjamin e o estímulo para que ele aprofundasse sua aproximação ao marxismo, mas também a influência decisiva que ela exerceu em sua trajetória intelectual, no que se refere inclusive a temas e estilo de escrita. Para uma exaustiva demonstração desses fatos, ver Mcgill (2008). Ver, ainda, Buck-Morss (1989, p. 14-15, 21), Chisholm (2009, p. 254-255) e Ingram (2002).
}

UFRJ, Doutor (PUC-Rio). Brasileiro, residente em Rio de Janeiro, Email: 
É nos casos em que os conflitos humanos se relacionam de maneira mais objetiva com bens materiais que se abre o domínio dos meios puros. Por essa razão, a técnica no sentido mais amplo do termo é o seu caminho mais apropriado. Seu exemplo mais profundo talvez seja o diálogo, considerado como técnica da civilidade no entendimento. (...) ...existe uma esfera da nãoviolência no entendimento humano que é totalmente inacessível à violência: a esfera própria da "compreensão mútua", a linguagem. (idem, p. 139)

É preciso juntar a isso a ideia de que "uma resolução de conflitos totalmente não-violenta jamais pode desembocar num contrato de direito". Nos encontramos, aqui, no coração de uma visão possível da utopia antropófaga, em que o equilíbrio saudável da vida comunitária aparece como imagem de uma sociedade sem contrato, sem rei nem lei. E estamos também no coração da concepção messiânica da revolução, única imagem possível de uma violência que não vem para instaurar um novo direito, nem manter o velho, mas para fundar "uma nova era histórica" (idem, 155).

Apenas indicamos, aqui, a relação entre revolução e as dimensões erótica e amorosa na obra e vida de Benjamin, enquanto possível "esfera de entendimento inacessível à violência" (preciosas análises a esse respeito encontram-se no ensaio "Benjamin's Gender, Sex, and Eros" de Dianne Chisholm, 2009); relação também presente na poética e na prosa de Oswald, em torno do matriarcado e da sexualidade. ${ }^{12}$

\section{Conclusão}

Nossa proposta foi a de indicar, de modo ainda incipiente, alguns temas e problemas que aproximam Benjamin e Oswald no que diz respeito à dimensão política de suas obras, e que implicam uma certa condição de outsiders diante da política militante, partidária, institucional. Para ambos, ainda que por caminhos muito distintos, a revolução é uma destruição da ordem existente que mobiliza forças passíveis de serem conhecidas apenas dialeticamente, uma destruição que pressupõe um trabalho teórico e

\footnotetext{
12 Ver CEPPAS (2017).
}

UFRJ, Doutor (PUC-Rio). Brasileiro, residente em Rio de Janeiro, Email: filcepps@gmail.com 
imagético, também prático, de atenção às forças capazes de fazer falar no agora o primitivo recalcado na história, movimento que se relaciona de modo oblíquo com a experiência erótica e a crítica ao patriarcado.

Tanto Benjamin quanto Oswald, em fidelidade às questões acima esboçadas, não conseguiram (ou mesmo evitaram) se inserir na militância política, e foram por ela rejeitados, em função das exigências geradas nessa fidelidade; exigências que em Oswald tem o nome de antropofagia e em Benjamin, messianismo. Nada mais natural, portanto, que os militantes comunistas, aqui e na Europa, desconfiassem dos esforços de ambos em se aproximar do universo da praxis marxista partidária. A complexidadeobscuridade das ideias de Benjamin e a dimensão fragmentária e histriônica das sínteses selvagens de Oswald aprofundam a rejeição: em geral não se gosta do que não se entende (e podemos imaginar que os comunistas de então gostavam ainda menos quando os entendiam). A preocupação com o arcaico, assim como a ideia da linguagem e do amor como esfera própria da compreensão mútua aproximam as obras de Oswald e Benjamin enquanto terreno de enfrentamento e experimentação política, poética e filosófica; experimentação imagética e anti-burguesa plena de apelo revolucionário.

\section{REFERÊNCIAS}

ADORNO, Theodor \& BENJAMIN, Walter. The complete correspondence 1928-1940. Cambrigde: Harvard Univesrity Press, 1999.

ANDRADE, Oswald. Obras completas 6. Do Pau-Brasil à antropofagia e às utopias. Rio de Janeiro: Civilização Brasileira, 1972.

BAUDELAIRE, Charles. Sobre a modernidade. São Paulo: Ed. Paz e Terra, 1988.

BAUDELAIRE, Charles. Oeuvres Complètes II, Juvenilia. Éds Louis Conard, 1952.

BENJAMIN, Walter. "Sobre a crítica do poder como violência", "Experiência e pobreza" e "Johann Jakob Bachofen", In_: O anjo da história, trad. João Barrento, Belo Horizonte: Autêntica, $201 \overline{6 .}$ 
religião. São Paulo: Boitempo, 2013a.

"Bernoulli, Bachofen", In_: O capitalismo como

."Para a crítica da violência", In__: Escritos sobre mito e

linguagem. São Paulo: Duas Cidades, 2013b.

. Passagens. Belo Hozironte/São Paulo: Ed.

UFMG/Imprensa Oficial do Estado de São Paulo, 2007.

Gesammelte Scrifthen. Frankfurt am Main: Suhrkamp,

1991.

Obras Escolhidas III. Charles Baudelaire, um lírico no auge do capitalismo. São Paulo: Ed. Brasiliense, 1989.

BUCK-MORSS, Susan. The dialetics of seeing, Walter Benjamin and the Arcades Project. Cambridge: The MIT press, 1989.

CEPPAS, Filipe. "Antropofagia e diferenças: o matriarcado de Oswald como perspectiva anti-edipiana", Revista Latinoamericana del Colegio Internacional de Filosofia ํㅡㄹ, p.25-42, 2017.

CHISHOLM, Dianne. "Benjamin's Gender, Sex, and Eros", In_: Rolf J. Goebel (ed) A Companion to the Works of Walter Benjamin. Nova York: Camden House, 2009.

FABRI, Bruno. "Experiência, barbárie, antropofagia: Oswald de Andrade, contemporâneo de Walter Benjamin", In__: Cadernos Benjaminianos, n. 3, Belo Horizonte, jan.-jun. 2011, p.26-33

GUNNING, Tom. "The Exterior as Intérieur: Benjamin's Optical Detective", In_: McLaughlin \& Rosen (eds). Durham: Duke University Press Book, 2003.

HELENA, Lucia. Totens e tabus da modernidade brasileira: símbolo e alegoria na obra de Oswald de Andrade. Rio de Janeiro: Tempo Brasileiro/UFF, 1985.

HOLANDA, Sérgio Buarque. Visão do paraíso. São Paulo: Brasiliense, 2000. INGRAM, Susan. "The writing of Asja Lacis", New German Critique 86, 2002, p.159-177.

KONDER, Leandro. "Benjamin et la révolution", In_: Ingrid Scheurmann \& Konrad Scheurmann. Pour Benjamin, Bonn: AsKi, 1994.

MAIO, Sandro Roberto. Leituras da modernidade de Baudelaire: montagens teórico-ficcionais em Walter Benjamin e Oswald de Andrade. In Crioula, no 8, nov, 2010. Revista 
MCGILL, Justine. "The porous coupling of Walter Benjamin and Asja Lacis", Journal of the theoretical humanities. Vol.13 number 2, august, 2008, p.59-72.

NODARI, Alexandre. "A posse contra a propriedade": pedra de toque do Direito Antropofágico. Dissertação de mestrado, UFSC, 2007.

SILVA, Maria da Silva. "Encontros de narrativas entre Oswald de Andrade e Walter Benjamin". Acta Scientiarum. Humam and Social Sciences, Maringá, v. 39, n. 2, p. 121-130, May-Aug., 2017.

SILVA, Jorge Augusto. Ano 374 da deglutição do bispo Sardinha, a escrita da história nos poemas Pau-Brasil,. Dissertação de mestrado, UFBA, 2013. 